Research Article

\title{
Microstructures, Mineral Compositions, and Mechanical Properties of Red-Layers in Southern China
}

\author{
Huizhi Zhang $\mathbb{C}^{1,2}$ and Jifeng Liu $\mathbb{D}^{1,2}$ \\ ${ }^{1}$ Key Laboratory of Engineering Materials and Structural Reinforcement, Sanming University, Fujian Province University, \\ Fujian, China \\ ${ }^{2}$ Department of Architecture and Civil Engineering, Sanming University, Fujian, China \\ Correspondence should be addressed to Huizhi Zhang; zhz888_1981@163.com
}

Received 8 January 2018; Accepted 21 May 2018; Published 5 July 2018

Academic Editor: José A. Correia

Copyright (c) 2018 Huizhi Zhang and Jifeng Liu. This is an open access article distributed under the Creative Commons Attribution License, which permits unrestricted use, distribution, and reproduction in any medium, provided the original work is properly cited.

\begin{abstract}
In order to reveal the water-induced damage mechanism and mechanical properties of red-layers in Southern China, typical redlayer samples are experimentally studied by scanning electron microscope (SEM), energy spectrum analysis, XRD, and mechanical tests. The results show that some red-layer samples contain a large number of smectite and illite-smectite mixed-layer clay minerals and their microstructures are mainly stacked microaggregates in which mutual agglomeration is formed by flake and tabular clay particles. Widespread distribution micropores and fractures in microaggregates provide the necessary moisture migration channels. The various cemented materials produce a kind of irreversible structural strength, and this strength is vulnerable for the aqueous medium conditions. The influence of microstructures and mineral compositions on red-layer mechanical properties is discussed. The results could provide the reference for further research about the water-induced damage mechanism of red-layers in Southern China.
\end{abstract}

\section{Introduction}

There are widely distributed red-layers in Southern China, for example, in Yunnan, Guangdong, Guizhou, and Sichuan provinces. The red-layers in those areas are brownish red or brownish yellow clay soil or soft rock, which is the laterized product of carbonate rock. Mainly including expansive clay minerals, soluble minerals, or organic minerals, the redlayers have many special engineering geological properties in comparison with common clay. In general, most redlayers have high water content, high plasticity, large pore ration, and low density, the physical and mechanical properties of red-layers are easily affected by water $[1,3]$. Engineering construction disturbance or water intrusion will induce damage in microstructures or/and change in mineral compositions, which could cause the red-layers rapidly expanse and collapse. Such complex properties bring a serious impact on the safety and stability of major engineering construction in those regions [4-9]; for instance, squeezed muck wear formation ahead of shield cutters seriously affected Guangzhou Metro Lines construction speed (Figure 1, $[10,13])$.

The physical and mechanical characteristics of red-layers or clay soil have been widely studied. Mendes and Toll [14] revealed that the critical state stress ratio is not affected by the initial water content, and the volumetric behavior differences lead to sample property differences when samples are subjected to wetting and drying after compaction. Chavali et al. [15] investigated the alkali-induced swelling in nonswelling kaolinitic clays, and the results showed that the magnitude of alkali-induced swelling in the clays is attributed to dispersion of clay particles and formation of new mineral. Harjupatana et al. [16] developed a noninvasive method for simultaneous measurement of the 3D displacement field and the water content distribution of a wet solid material and applied it in validating models involving transport of water and the resulting swelling deformation of bentonite. Aziz et al. [17] revealed that the observed soil 


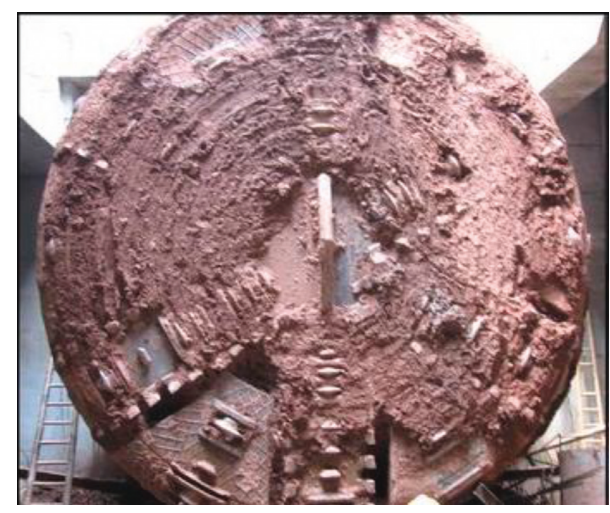

Figure 1: Squeezed muck wear in shield cutters, Guangzhou Metro Line.

behavior could be critical for embankments constructed with rock-fill materials. Wong et al. [18] reviewed the research of strength and stiffness reduction in rocks attributed to an increase in water content in recent years. Ma et al. [8] conducted a series of constant water content triaxial tests on statically compacted specimens, the results showed that Yunnan red clay failure envelope is affected by its saturation degree, and a new semiempirical shear strength model in terms of degree of saturation could be proposed. Zhao et al.'s [6] experimental results showed that the damage form of the remodeled red clay changed from the ballooning excessive damage to shear failure with the reduction of water content. Zhang et al. [7] proposed and verified a X-ray computed tomography (CT) method to nondestructively measure the water content of red clay cylinders, and the test results showed that the rainfall, ground water level, and degree of compaction are factors that could significantly affect the moisture migration distance and migration rate. Hu et al. [9] investigated the effect of water content on the stable swelling capacities, swelling process, and characteristics of red bed mud-stone, the results revealed that there were three phases exiting in the confined free sweeling test, and vertical loads greatly restrained the confined swelling. However, limited studies have been conducted on the relationship of red-layer mechanical properties and its microstructure and composition changes. Some studies showed that changes in mineral compositions and microstructures yielded macroscopic degradation of mechanical parameters [3, 19-21]; therefore, the relationships of mechanical behaviors and microstructure and mineral compositions of red-layers should be fully investigated.

In this study, for investigating mechanical behaviors of red-layers influenced by microstructures and mineral compositions, a series of experimental tests are conducted on redlayer specimens which are sampled in Guangzhou Metro Line.

\section{Sample Preparation}

The typical red-layer specimens are sampled at Tiyu West road station, Zhujiang new town station, Wushan road station, Kecun road station, and Tianhe road station of Guangzhou Metro Line, separately. The details of specimens are given in Table 1. For other details of the samples, see Liu and Zhang [22]. The samples' lithologies are shown in Figure 2.

The specimens for all mineral XRD tests are prepared as follows: (1) the core of the rock or soil sample block is dried for $48 \mathrm{~h}$ in an electric oven below $60^{\circ} \mathrm{C}$, and then the specimens are cooled to room temperature. (2) $1-2 \mathrm{~g}$ of the samples is crushed to less than $1 \mathrm{~mm}$ particle size by a grinding machine, and then the particles are ground to the whole particle size of less than $40 \mu \mathrm{m}$. (3) The aluminum sample frame is closely placed on the flat glass plate, and the sample powder is spooned into the $20 \mathrm{~mm} \times 18 \mathrm{~mm}$ framework and is vertically compressed for molding. The lower side is adopted for the test surface.

The sample preparation for XRD tests of the relative clay mineral content is as follows: (1) the air-dried sample is crushed to a particle size of less than $1 \mathrm{~mm}$, the crushed power is placed into the beaker, and then the sample is soaked with distilled water and dispersed by the ultrasonic treatment. (2) The suspension with a particle size of less than $2 \mu \mathrm{m}$ is drawn and centrifuged for accelerating the clay mineral settlement. (3) The centrifuged sample is then dried for $48 \mathrm{~h}$ in an electric drying oven below $60^{\circ} \mathrm{C}$, and the dried sample is ground to finer particles by an agate mortar. (4) $40 \mathrm{mg}$ of the dried sample particle is placed into $10 \mathrm{ml}$ tubes and $0.7 \mathrm{ml}$ of distilled water is added into the tubes; after complete stirring, the clay mineral is fully dispersed by the ultrasonic treatment, the suspension is quickly placed on glass slides and air-dried, and then a natural directional sheet (N) is prepared. (5) After the experiment, the glycol vapor is used to make a glycol saturated tablet (NG) by heating a natural directional sheet $(\mathrm{N})$ at $40-50^{\circ} \mathrm{C}$ constant temperature for $7 \mathrm{~h}$, and then the sheet is cooled to room temperature. (6) At the end of the experiment, the glycol saturated tablet (NG) kept at $550^{\circ} \mathrm{C}$ constant temperature for $2 \mathrm{~h}$, and then the specimen is cooled to room temperature to make a heating sheet $\left(550^{\circ} \mathrm{C}\right)$.

There is a time interval between the sampling and the test. For more realistic viewing of microstructures of the redlayers, it is necessary to remake the specimen. The specimens for SEM analysis are prepared as follows: (1) After removing surface, the samples are immersed in pure anhydrous alcohol for 30 minutes, and then the pure anhydrous alcohol is replaced with anhydrous alcohol to ensure the purity of the alcohol before the test. The purpose of using anhydrous alcohol is to ensure original microstructures of the specimen, because anhydrous alcohol is easily evaporated and carries away the residual moisture in the samples. (2) The samples are air-dried and then are cohered on the table, and heavy metal membrane are sprayed on surfaces to avoid discharge phenomenon. (3) $30 \mathrm{~mm}$ thickness heavy metal membrane is sprayed on the morphology analysis samples. The energy spectrum analysis samples are without metal spray coating to avoid the metal film effects on test precision.

\section{Experimental Test}

The typical tests for analyzing the microphysical property of red-layers are SEM analysis which include micromorphology 
TABLE 1: Microexperimental soil samples of typical red-layers.

\begin{tabular}{lcccccc}
\hline Number & Sampling site & $\begin{array}{c}\text { Sampling depth } \\
(\mathrm{m})\end{array}$ & Corings & $\begin{array}{c}\text { Total } \\
\text { sampling }\end{array}$ & Lithology & $\begin{array}{c}\text { Disturbed or } \\
\text { not }\end{array}$ \\
\hline 1 & Tiyu west road station & 16 & 3 & 12 & Moderately weathered red clay & Disturbed \\
\hline 2 & Zhujiang new city & $17.2-17.8$ & 3 & 12 & Red clay & Disturbed \\
\hline 3 & Station & 12 & 3 & 12 & $\begin{array}{c}\text { Moderately to strongly weathered red } \\
\text { clay }\end{array}$ & Undisturbed \\
\hline
\end{tabular}

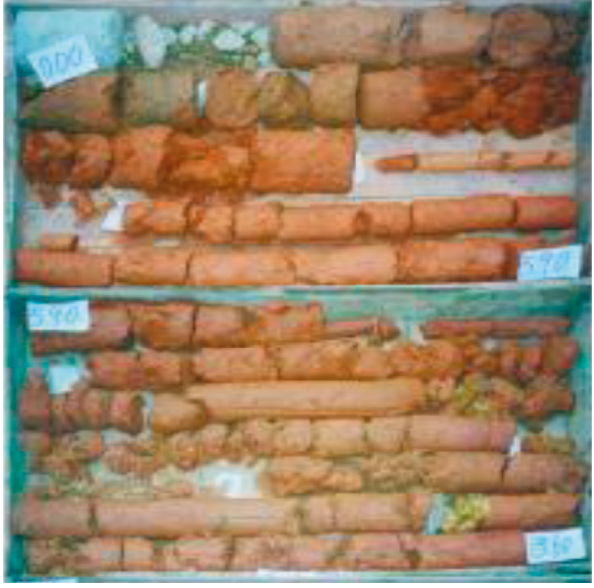

(a)

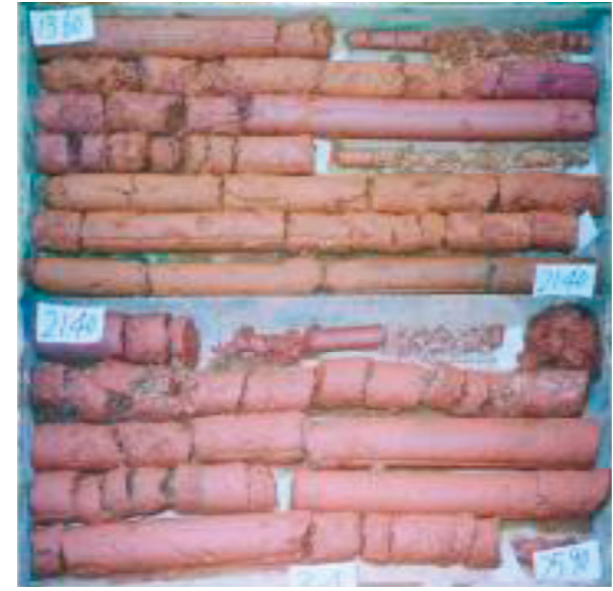

(b)

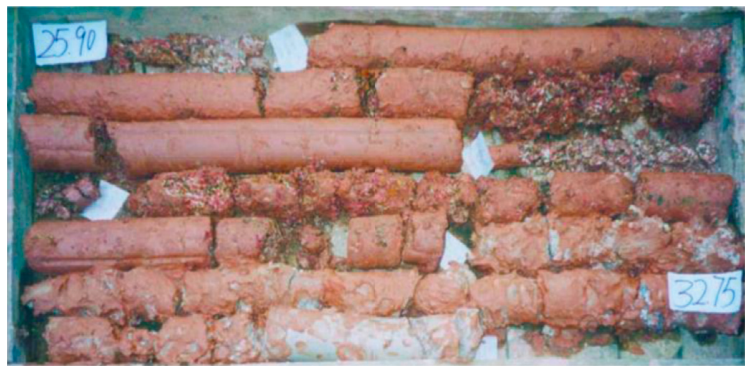

(c)

Figure 2: Corings of Wushan road station in Guangzhou Metro Line 3.

scanning, energy spectrum analysis, and XRD which include clay mineral and total mineral analysis. Samples are prepared in accordance with the test requirements. The used instruments are LEO-435VP scanning electron microscope, FEI Quanta200 field emission scanning electron microscope, and D/MAX-2500 X diffraction instrument.

\section{Results}

4.1. Analysis of Scanning Electron Microscope and Energy Spectrum Test Results. The mineral compositions are expressed as follows: $\mathrm{C}=$ chlorite; $\mathrm{I}=$ illite; $\mathrm{S}=$ smectite; $\mathrm{Na}-\mathrm{F}=$ albite; $\mathrm{I} / \mathrm{S}=$ illite and smectite mixed layer; $\mathrm{K}=$ kaolinite; $\mathrm{K}-\mathrm{F}=$ kaolinite and potash feldspar mixed layer; $\mathrm{Q}=$ quartz crystal; $\mathrm{I} / \mathrm{C}=$ illite and chlorite mixed layer; $\mathrm{C} / \mathrm{S}=$ chlorite and smectite mixed layer.

The SEM images of Tiyu west road station red clay samples are shown in Figure 3, which shows that the soil samples are relatively loose and the larger pores between the particles are about $100-200 \mu \mathrm{m}$ with the great connectivity. The samples contained a lot of honeycomb and flaky illite and smectite mixed layer, a small amount of needle-like chlorite and flake-flocculent chlorite and smectite mixed layer, and authigenic polyhedral quartz and strip albite crystal existing in particles.

The SEM images of Zhujiang new city station red clay samples are shown in Figure 4. It could be known from Figure 4 that the soil samples are relatively loose, and the larger pores between the particles are with the diameter of $30-100 \mu \mathrm{m}$ with the good connectivity. The samples contain a large number of flake-flocculent illite and smectite mixed layer, illite and chlorite mixed layer, layered illite, and flake kaolinite. The local parts of the samples contain leached surface potash feldspar crystals. Under the magnification of 9440-20,000 times, a large number of flake aggregates could be observed.

The SEM images of Wushan road station red clay samples are shown in Figure 5. One could see from Figure 5 that the red 


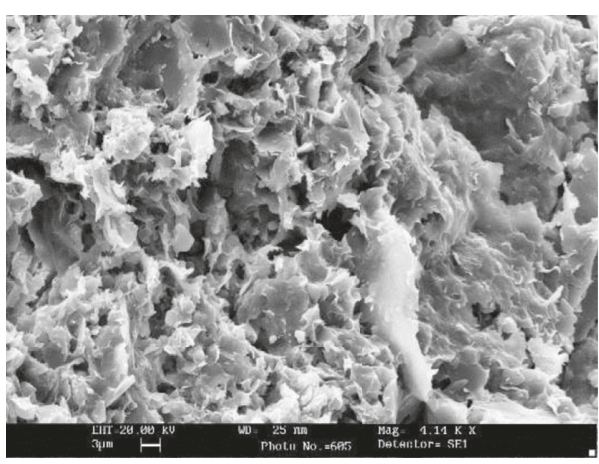

(a)

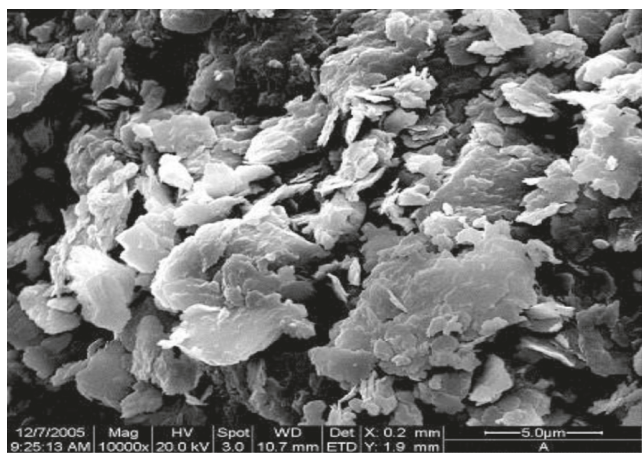

(b)

FIgURE 3: SEM images of red clay samples in Tiyu west road station. (a) $\times 4140$ honeycomb I/S with a small amount of needle-like C. (b) $\times 10,000$ flake-flocculent I/S.

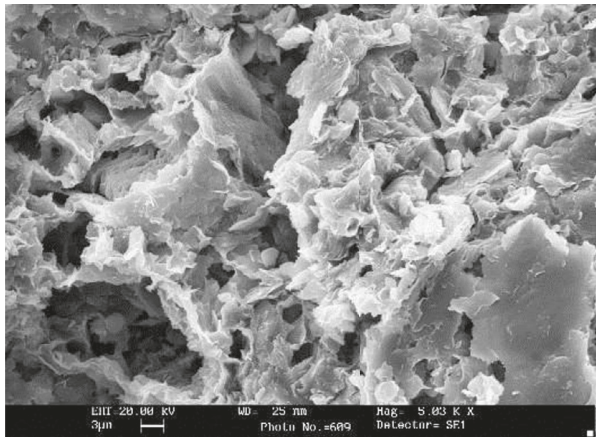

(a)

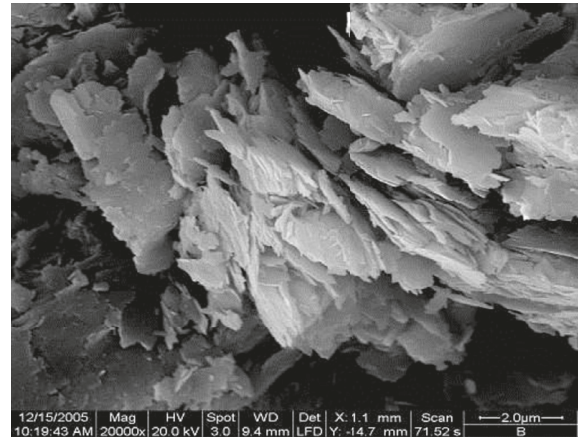

(c)

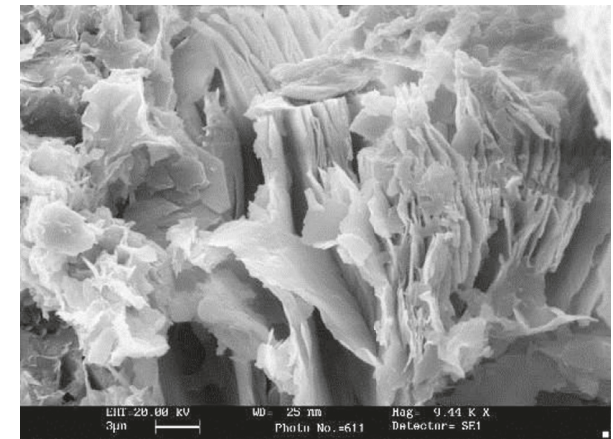

(b)

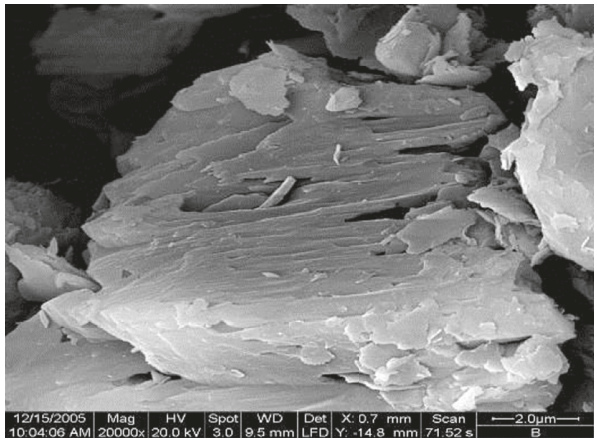

(d)

FIGURE 4: SEM images of red clay samples in Zhujiang new city station. (a) $\times 5030$ flake-flocculent I/C and quartz crystal. (b) $\times 9440$ flake I and $\mathrm{K}$ and flake-flocculent I/S. (c) $\times 20,000$ leaf shaped and laminated C. (d) $\times 20,000$ leached K-F crystal, containing fibrous sepiolite.

clay samples are loose, the larger pores between the particles are with the diameter of $30-50 \mu \mathrm{m}$, and the pores have the good connectivity. The samples contain a large number of honeycomb, flake, and flake-filamentous illite, smectite mixed layer, and curly flake smectite. And a small amount of needlelike chlorite and filamentous illite with the dissolved albite crystals are observed as well. Figure 5(b) shows the lamellar stack dimers under the magnification of 40,000 times, which is the important mesostructure characteristic of the complex red-layer by test observation. It can be estimated from Figure 5(c) that the thickness of the polymer monolithic stack is approximately $10 \AA(1 \mathrm{~nm})$, and these large amount of pores and a laminated polymers provide favorable conditions for water intrusion and damage of red-layers.

The energy spectrum analysis of red clay samples are carried out by the LINKISIS-type energy spectrometer; for simplicity of consideration, only the scanning images of Tiyu west road station red clay samples are given (Figure 6). Tiyu west road station red clay samples contain a large number of illite and smectite mixed layer, chlorite and smectite mixed layer, massive albite crystals, and filamentous chlorite. There are massive authigenic quartz crystals spreading between the particles. Zhujiang new city station red clay samples contain a lot of orderly flake, disorderly 


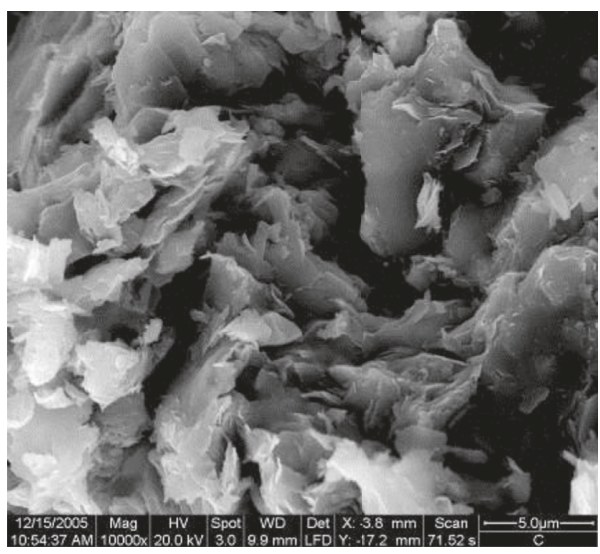

(a)

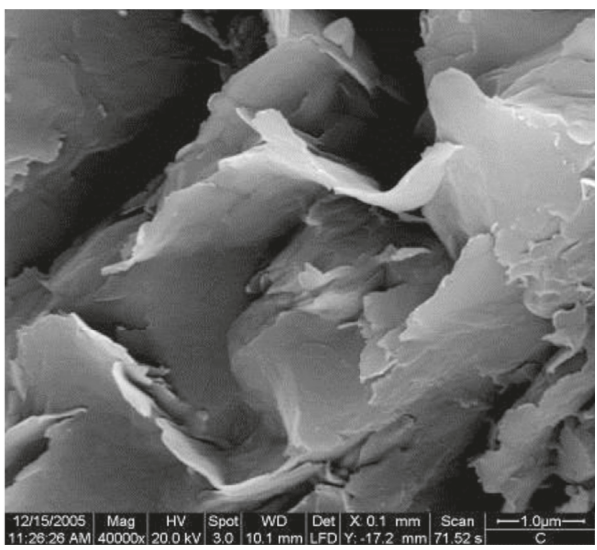

(b)

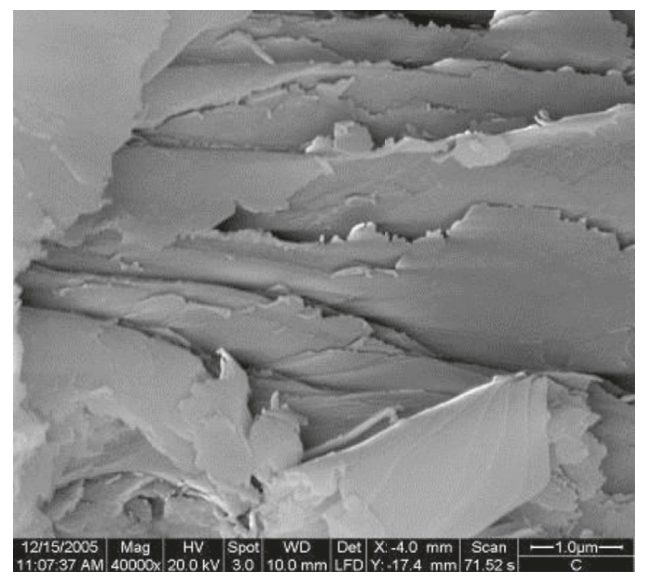

(c)

FIGURE 5: SEM images of red clay samples in Wushan road station. (a) $\times 10000$ filament I/S. (b) $\times 40,000$ the typically flake I/S. (c) $\times 40,000$ flake I/S, curled lamellar S.

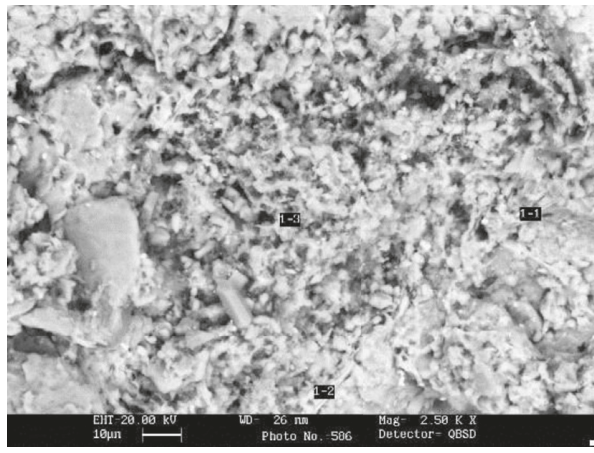

(a)

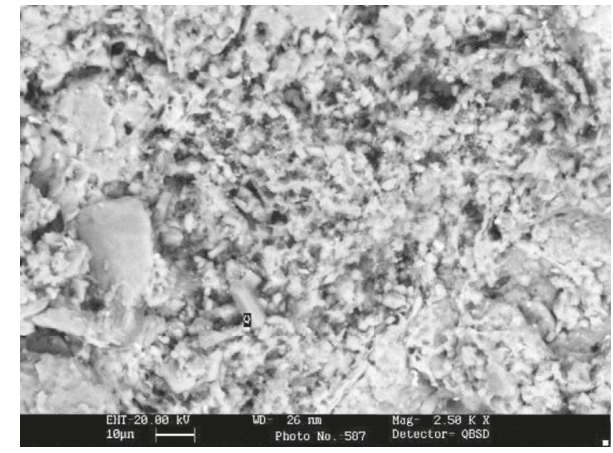

(b)

Figure 6: Energy spectrum pictures of red clay samples in Tiyu west road station. (a) $\times 25001-1$ I/S; 1-2 I/S; 1-3 C/S. (b) $\times 2500$ 1-4 authigenic quartz crystal.

flake-filamentous illite, and smectite mixed layer. There are bulk albite crystals existing between the local layers. There is a trend that a large number of kaolinite transform to illite. Wushan road station red samples contain a large number of aflocculent illite, smectite mixed layer, and flake chlorite. The local massive albite crystals and quartz crystals also exist in the samples.
4.2. Analysis of X-Ray Diffraction Results. The three clay minerals and three nonclay minerals samples are tested by the XRD. The results are analyzed in accordance with "X-ray diffraction analysis of the relative content of clay minerals in sedimentary rocks" and "X-ray diffraction quantitative analysis of the clay mineral aggregate and common nonclay minerals in sedimentary rocks" $[23,24]$. 


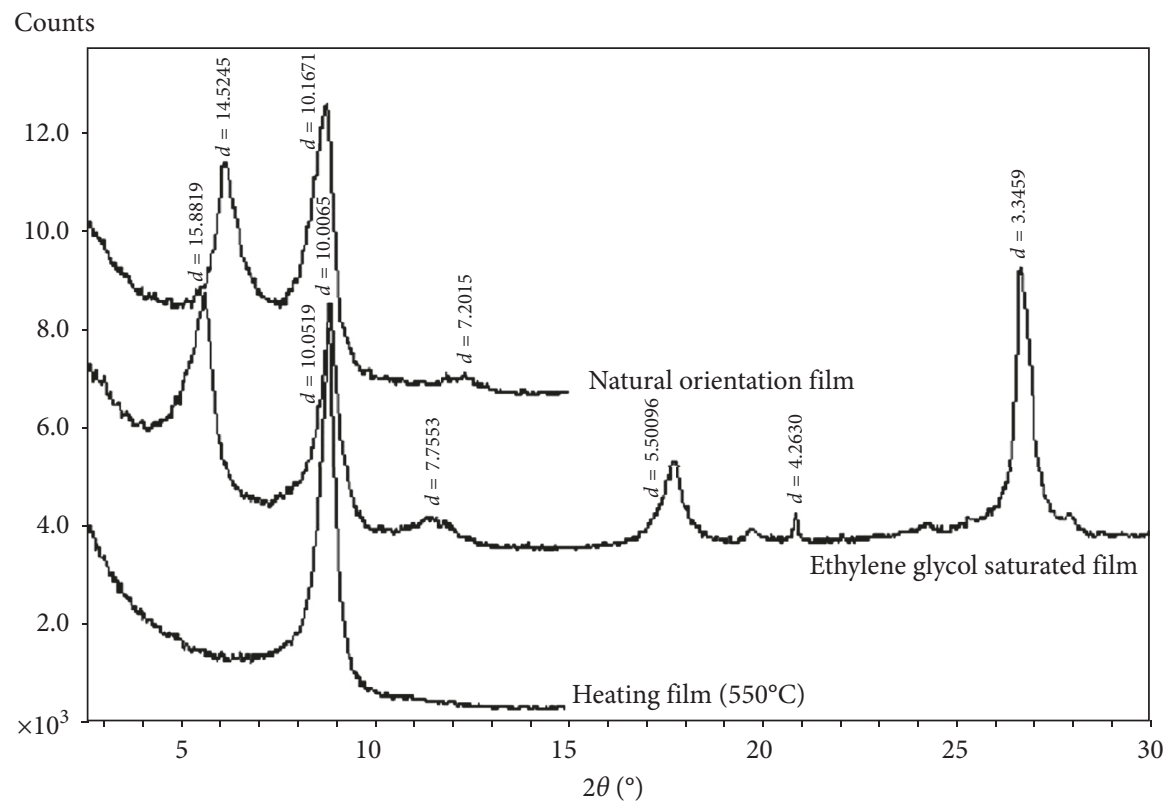

FIgURE 7: X-ray diffraction pattern of red clay in Tiyu west road station.

TABLE 2: XRD results of the remaining samples.

\begin{tabular}{|c|c|c|c|c|c|c|c|c|c|c|c|}
\hline \multirow[t]{2}{*}{ Number } & \multirow[t]{2}{*}{ Sampling site } & \multirow[t]{2}{*}{$\begin{array}{l}\text { Sampling depth } \\
(\mathrm{m})\end{array}$} & \multirow[t]{2}{*}{ Lithology } & \multicolumn{6}{|c|}{$\begin{array}{l}\text { Clay mineral relative } \\
\text { content }(\%)\end{array}$} & \multicolumn{2}{|c|}{$\begin{array}{c}\text { Mixed } \\
\text { layer ratio } \\
(\% \mathrm{~S})\end{array}$} \\
\hline & & & & $\mathrm{S}$ & $\mathrm{I} / \mathrm{S}$ & I & Kao & $\mathrm{C}$ & $\mathrm{C} / \mathrm{S}$ & $\mathrm{I} / \mathrm{S}$ & $\mathrm{C} / \mathrm{S}$ \\
\hline KD01 & Tiyu west road station & 16 & Moderately weathered red clay & 54 & - & 46 & - & - & - & - & - \\
\hline KD02 & $\begin{array}{l}\text { Zhujiang new city } \\
\text { station }\end{array}$ & $17.2-17.8$ & Red clay & 64 & - & 36 & - & - & - & - & - \\
\hline KD03 & Wushan road station & 12 & $\begin{array}{c}\text { Moderately to strongly weathered red } \\
\text { clay }\end{array}$ & 2 & 46 & 42 & 4 & 6 & - & 15 & - \\
\hline KD04 & $\begin{array}{l}\text { Zhujiang new city } \\
\text { station }\end{array}$ & $18.1-19.0$ & Sandstone & - & 47 & 44 & 3 & 6 & - & 15 & - \\
\hline KD05 & Kecun station & 27.6 & Red sandstone & 3 & 75 & 20 & 1 & 1 & - & $40 / 25$ & - \\
\hline KD06 & Tianhe station & 16 & Shield excavated soil & - & - & 56 & 38 & 6 & - & - & - \\
\hline
\end{tabular}

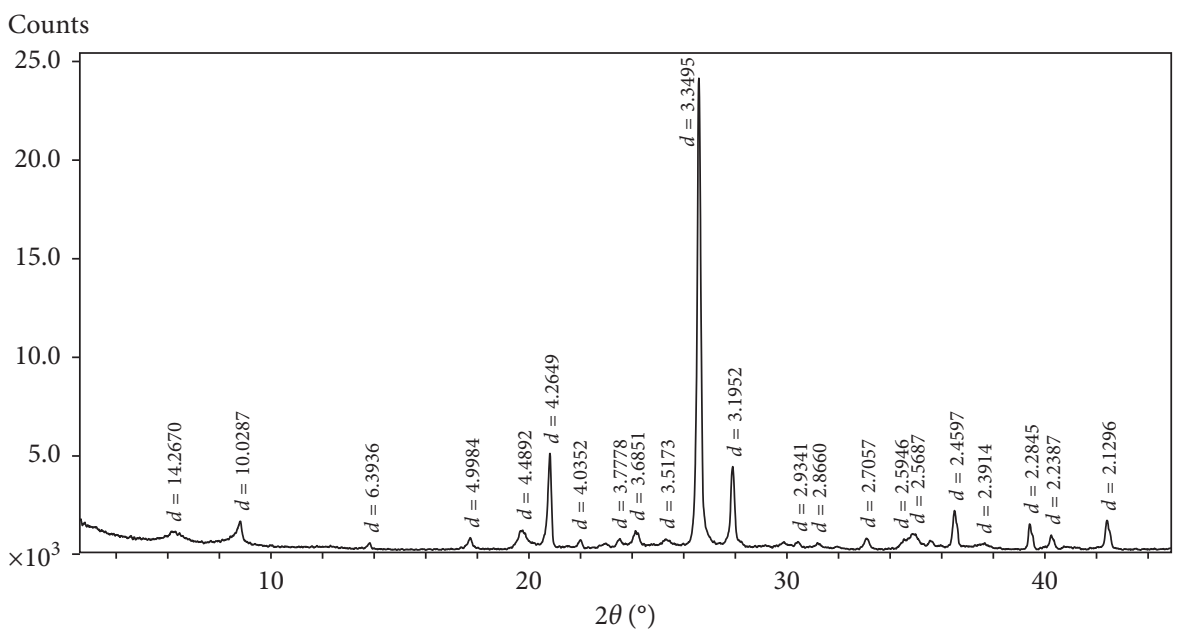

FIgURE 8: Total mineral X-ray diffraction pattern of red clay samples in Zhujiang new city station. 
TABLE 3: All mineral XRD test results.

\begin{tabular}{|c|c|c|c|c|c|c|c|c|c|c|}
\hline \multirow{2}{*}{ Number } & \multirow{2}{*}{ Sampling site } & \multirow{2}{*}{$\begin{array}{l}\text { Sampling } \\
\text { depth }(\mathrm{m})\end{array}$} & \multirow{2}{*}{ Lithology } & \multicolumn{6}{|c|}{ Mineral type and content (\%) } & \multirow{2}{*}{$\begin{array}{c}\text { Total clay } \\
\text { minerals (\%) }\end{array}$} \\
\hline & & & & Quartz & Feldspar & Plagioclase & Calcite & Hematite & Barite & \\
\hline PKD01 & $\begin{array}{c}\text { Tiyu west road } \\
\text { station }\end{array}$ & 16 & $\begin{array}{l}\text { Moderately weathered } \\
\text { red clay }\end{array}$ & 47.2 & - & 14.5 & - & 2.8 & - & 35.5 \\
\hline PKD02 & $\begin{array}{l}\text { Zhujiang new } \\
\text { city station }\end{array}$ & $17.2-17.8$ & Red clay & 45.7 & - & 10.9 & - & 3.5 & - & 39.9 \\
\hline PKD03 & $\begin{array}{l}\text { Wushan road } \\
\text { station }\end{array}$ & 12 & $\begin{array}{l}\text { Moderately to strongly } \\
\text { weathered red clay }\end{array}$ & 33.6 & - & 14.8 & 12.2 & 2.8 & - & 36.6 \\
\hline PKD04 & $\begin{array}{l}\text { Zhujiang new } \\
\text { city station }\end{array}$ & $18.1-19.0$ & Sandstone & 27.7 & - & 5.4 & 21.1 & 5.7 & - & 40.1 \\
\hline PKD05 & Kecun station & 27.6 & Red sandstone & 44.1 & 8 & 6.1 & 7.4 & 1.4 & - & 33.0 \\
\hline PKD06 & Tianhe station & 16 & Shield excavated soil & 32.9 & 15.6 & 6.5 & - & & - & 45.0 \\
\hline
\end{tabular}

For the clay mineral XRD test, each soil sample has three piece directional diffraction and three diffraction patterns named "natural directional sheet" $(\mathrm{N})$, "ethylene glycol" $(\mathrm{NG})$, and "saturated tablet $550^{\circ} \mathrm{C}$ heating plate" $[25,27]$. The clay mineral compositions can be identified according to the diffraction characteristics of three diffraction patterns such as diffraction peak or diffraction angle and peak value. The relative content can be determined by diffraction intensity. If the pattern is not very standard characteristic, or the diffraction patterns are between the two components, it can be identified as a mixed layer of illite and smectite, or chlorite and smectite mixed layer.

For simplicity of consideration, only diffraction pattern of Tiyu west road station red clay samples is shown in Figure 7. It is revealed that the soil samples mainly contain smectite and illite, and the relative content of smectite and illite is $54 \%$ and $46 \%$, respectively. Other clay mineral components in the diffraction are not found. The XRD results of the remaining samples are shown in Table 2 .

The XRD results of typical nonclay minerals of Zhujiang new city station samples are shown in Figure 8. It is shown that the content of clay minerals is $39.9 \%$, and the main nonclay minerals are $45.7 \%$ quartz and $10.9 \%$ plagioclase, respectively. The hematite content is $3.5 \%$, and other nonclay minerals are not found. The test results are shown in Table 3.

\section{Conclusion and Discussion}

The typical Southern China red-layers rock and soil samples are experimentally studied by SEM, energy spectrum analysis, XRD, and mechanical tests, and then the results are analyzed. Through this research, we can draw the following conclusions:

(1) The local area of red-layers in Southern China contains a large amount of smectite, illite, and smectite mixedlayer clay minerals. The microstructures are mainly layered or stacked microaggregates which are formed by the agglomeration of flaky and flat clay particles. The penetrated or partially penetrated cracks separate the lamellar structures. The stacked microaggregates are the main structural basic units which make up the microstructures and determine the swelling and shrinkage properties of the complex red-layers. The large amount of fine-grained expansion clay minerals is the main material basis for determining the complex red-clays properties. It is also an important internal factor which impacts its engineering properties such as water swelling, easily sliming, and strong viscosity [21, 28-30].

(2) The cohesion of various cemented materials in the stacked microaggregates enhances the structural connection between microaggregates of complex red soils, and the cohesion results in a certain structural strength. This structural strength is also a kind of irreversible bond strength which is formed by the physical and chemical connection. While disturbed by construction or intruded by water, or the solution medium conditions in the rock or soil changed, the physical and chemical properties of cemented material will be very different, the structural strength of microaggregates will be lost, the total strength of the complex red-layers will decrease, and the rate of expansion will increase.

Influence of water content on the red-layer specimens is a complex phenomenon. The water-induced changes in microstructures and mineral compositions yield degradation of physical and mechanical parameters. Therefore, it is important to analyze the effects of water content on the degradation mechanisms of the specimens, as those conditions are considered during the aforementioned experiments.

The typical red-layers samples have layered or honeycomb microstructures and easily water swelling and weakening minerals such as chlorite and smectite. The pores between the particles have good connectivity which provides the water invasion tunnels. With the lower water content, the particles and layers make good contact with each other and the contact surface is flat and smooth, forming good microstructures which induce relatively good physical and mechanical properties.

During the process of water content increasing, the water infiltrates inside the specimen. The chemical reactions such as dissolution and corrosion occur in the mineral particles, and the chemical migration and dissolution occur at the cemented 
or contact surfaces between mineral particles, which can make the mineral compositions and microstructures change and the macro physical and mechanical degradation of the specimens.

Since the red-layers specimens comprises many minerals which can easily expand in the water, under water invasion the cracks would likely propagate by the stress concentrated at the crack endpoints [31]. It is favorable for the formation of infiltration channels and water molecules seepage within the specimens. The reactions between minerals and aqueous solution are accelerated, which increase the change in microstructures and promote the extension and coalescence of cracks and microtunnels. These factors are the mechanism of water content effect on the red-layer properties like shear strength, swelling, creep, and so on.

(3) The swelling behavior of microaggregates affects water migration, water-induced damage, and rheological properties. The test results show that the complex redlayers comprise a large amount of lamellar microaggregates formed by flaky and flat clay particles. The thickness of the monolithic slice is about $10 \AA$, the length of the monolith is $1-2 \mu \mathrm{m}$ and the width is $2-5 \mu \mathrm{m}$, and the lamellar microfracture width is $0.1-0.5 \mu \mathrm{m}$. There are the electrostatic repulsion, Van der Waals force, and hydration force existing between the stacking layers. The microaggregates structure arrangement state and the distance between the two relatively independent slices play a major role in the red clay hydration (volumetric chemical potential) at certain water content. The strong viscosity of redlayers under certain water content is due to its surface to surface microstructures in layered microaggregates.

\section{Data Availability}

The data of XRD, all mineral XRD test, direct shear test, and triaxial test under different water content which are used to support the findings of this study are included within the article.

\section{Conflicts of Interest}

The authors declare that they have no conflicts of interest.

\section{Acknowledgments}

The support of Fujian Province Natural Science Fund (Grant no. 2016J01743), Sanming University Science Research Development Fund (Grant no. JAT160454), and Fujian Province Young Teacher Education Research Project Fund (Grant no. B201603) is gratefully acknowledged.

\section{References}

[1] L. Song, Research of Micro-and Meso-Softening Mechanism of Red Beds Soft Rock with Water, Southwest Jiaotong University, Chengdu, Sichuan, China, 2014.

[2] Q. T. Bi, G. P. Jiang, and S. Y. Ding, "Water content influence on the shearing strength of red clay," Earth and Environment, vol. 33, no. 3, pp. 144-147, 2005.
[3] S. B. Li, J. Chen, and G. D. Yi, "Experimental study on the relationship between micro-characteristics and compressive strength of the red bed rock," Geotechnical Investigation and Surveying, vol. 4, no. 3, pp. 1-5, 2013.

[4] Q. L. Cui, H. N. Wu, S. L. Shen, and Y. S. Xu, "Geological difficulties of socket diaphragm walls in weathered granite in Shenzhen, China," Bulletin of Engineering Geology and the Environment, vol. 75, no. 1, pp. 263-273, 2016.

[5] H. J. Dong, X. F. Tan, Y. Zhao, S. H. Zhai, and Q. Yang, "Characteristic analysis of wear of cutters and excavation parameters of shield tunneling machine in red beds in Guangzhou," China Harbour Engineering, vol. 4, pp. 11-14, 2013.

[6] R. Zhao, S. Y. Zuo, W. Song, S. H. Li, and C. H. Huang, "Experiment and mechanism analysis of water contents on triaxial shear strength of the remodeled red clay of Guiyang," Hydrogeology and Engineering Geology, vol. 42, no. 5, pp. 90-95, 2015.

[7] J. H. Zhang, Q. P. Jiang, Y. Q. Zhang, L. L. Dai, and H. X. Wu, "Nondestructive measurement of water content and moisture migration of unsaturated red clays in South China," Advanced in Materials Science and Engineering, vol. 2015, Article ID 542538, 7 pages, 2015.

[8] S. K. Ma, M. S. Huang, P. Hu, and C. Yang, "Soil-water characteristics and shear strength in constant water content triaxial tests on Yunan red clay," Journal of Central South University, vol. 20, no. 5, pp. 1412-1419, 2013.

[9] W. J. Hu, Y. Ding, Z. Y. Xia et al., "Experimental study on confined swelling characteristic of redbed mudstone in Chongqing," Journal of Disaster Prevention and Mitigation Engineering, vol. 35, no. 5, pp. 607-611, 2015.

[10] W. B. Shi, Y. L. Lian, and X. L. Wang, "Discussion on the relationship between shear strength and water content of guiyang red clay," Subgrade Engineering, no. 4, pp. 80-85, 2011.

[11] Y. H. Wang, Q. X. Zhang, and P. C. Tian, "Effects of water content variation on the deformation and shear strength of laterite clay," Geotechnical Investigation \& Surveying, vol. 37, no. 7, pp. 10-13, 2009.

[12] J. X. Liu and Y. T. Liu, "Study on engineering characteristics and centrifugal test of red bed," Subgrade Engineering, no. 2, pp. 78-80, 2010.

[13] Y. Xu, C. Y. Zhou, Z. Liu, D. L. Su, and Z. C. Du, "Model tests for failure mechanism of typical soft rock slopes of red beds under rainfall in South China," Chinese Journal of Rock Mechanics and Engineering, vol. 35, no. 3, pp. 549-557, 2016.

[14] J. Mendes and D. G. Toll, "Influence of initial water content on the mechanical behavior of unsaturated sandy clay soil," International Journal of Geomechanics, vol. 16, no. 6, pp. 1-18, 2016.

[15] R. V. P. Chavali, S. K. Vindula, H. P. Reddy, A. Babu, and R. J. Pillai, "Swelling behavior of kaolinitic clays contaminated with alkali solutions: a micro-level study," Applied Clay Science, vol. 135, pp. 575-582, 2017.

[16] T. Harjupatana, J. Alaraudanjoki, and M. Kataja, "X-ray tomographic method for measuring three-dimensional deformation and water content distribution in swelling clays," Applied Clay Science, vol. 114, pp. 386-394, 2015.

[17] M. Aziz, I. Towhata, S. Yamada, M. U. Qureshi, and K. Kawano, "Water-induced granular decomposition and its effects on geotechnical properties of crushed soft rocks," Natural Hazards and Earth System Science, vol. 10, no. 6, pp. 1229-1238, 2010.

[18] L. N. Y. Wong, V. Maruvanchery, and G. Liu, "Water effects on rock strength and stiffness degradation," Acta Geotechnica, vol. 11, pp. 713-737, 2016. 
[19] H. F. Deng, M. L. Zhou, J. L. Li, X. S. Sun, and Y. L. Huang, "Creep degradation mechanism by water-rock interaction in the red-layer soft rock," Arabian Journal of Geosciences, vol. 9, no. 12 , pp. 601-613, 2016.

[20] M. C. Wend, L. S. Tsai, Y. M. Hsieh, and F. S. Jeng, "An associated elastic-visco-plastic constitutive model for sandstone involving shear-induced volumetric deformation," International Journal of Rock Mechanics and Mining Sciences, vol. 47, no. 5, pp. 1263-1273, 2010.

[21] Y. B. He and H. Liu, "Creep characteristics of red layer and tunnel surrounding rock displacement prediction based on PSO-SVM," Highway Engineering, vol. 41, no. 2, pp. 75-79, 2016.

[22] J. F. Liu and H. Z. Zhang, "Water content influence on properties of red-layers in Guangzhou metro line, China," Advances in Materials Science and Engineering, vol. 2017, Article ID 4808909, 12 pages, 2017.

[23] The People's Republic of China Oil and Gas Industry Standard, $X$ ray diffraction analysis method of the relative content of clay minerals in sedimentary rock, 1995.

[24] The People's Republic of China Oil and Gas Industry Standard, $X$ ray diffraction quantitative analysis method of the clay mineral aggregate and common non-clay minerals in sedimentary rocks, 1995.

[25] X. Y. Zhao and Y. Y. Zhang, Analysis of Clay Minerals and Clay Minerals, Ocean Press, Beijing, China, 1990.

[26] J. S. Yu, X. R Lei, J. H. Zhang et al., X-Ray Powder Mineral Identification Handbook (Map), Huazhong University of Science and Technology Press, Wuhan, China, 2011.

[27] C. H. Jiang, Polycrystalline X-Ray Diffraction Technology and Application, Chemical Industry Press, Beijing, China, 2014.

[28] Y. C. Wang and J. Chen, "Preliminary research on the relationship between microscopic structure and shear strength of red-bed soft rocks," Geoscience, vol. 27, no. 3, pp. 738-742, 2013.

[29] Z. K. Ding and A. Z. Lu, "Parameter identification of nonstationary creep equation of rocks," Rock and Soil Mechanics, vol. 25, no. 1, pp. 37-40, 2004.

[30] C. X. Chen, H. F. Lu, C. H. Yuan et al., "Experimental research on deformation properties of red-bed soft rock," Chinese Journal of Rock Mechanics and Engineering, vol. 29, no. 2, pp. 261-269, 2010.

[31] L. S. Tang, P. Zhang, and Y. Wang, "Propagation of the complex cracks in rocks II. Under water pressure and chemical damage," Acta Scientiarum Naturalium Universitatis Sunyatseni, vol. 42, no. 1, pp. 90-94, 2003. 


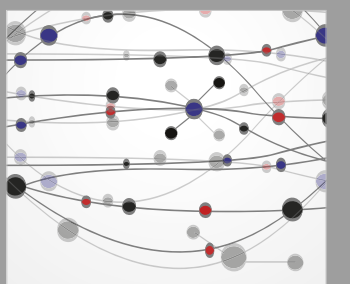

The Scientific World Journal
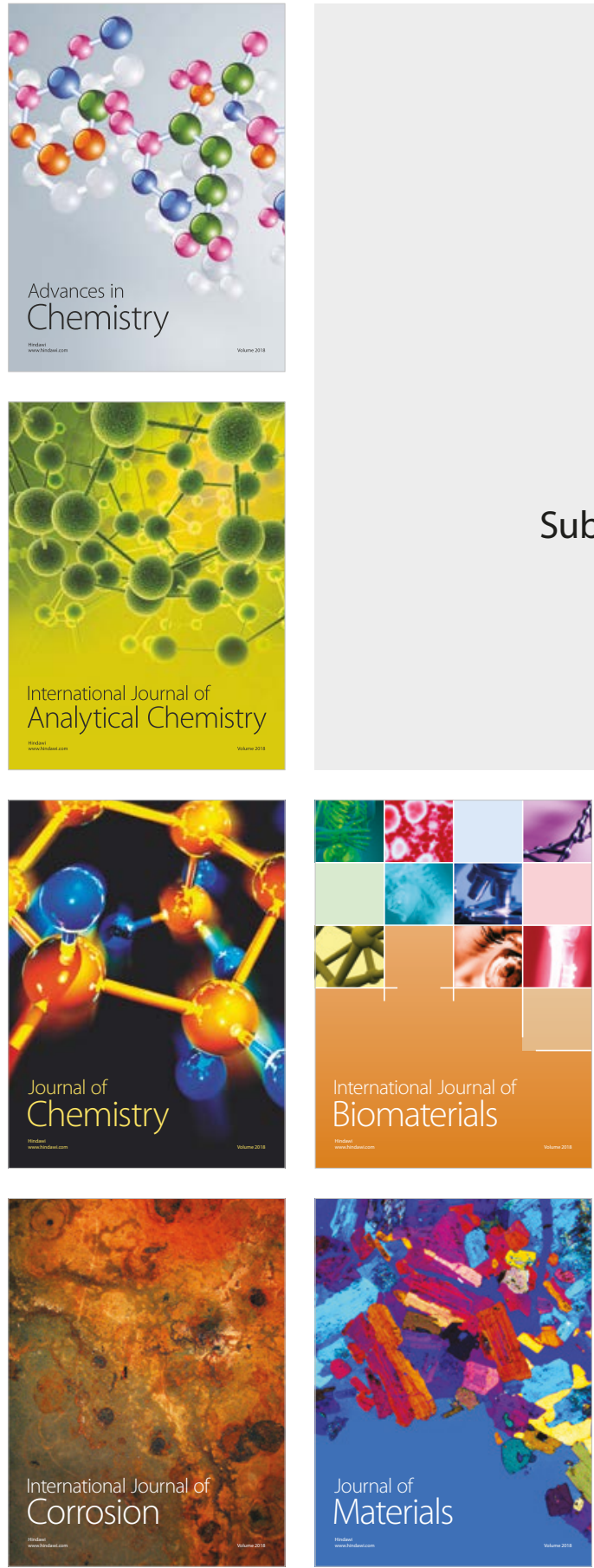

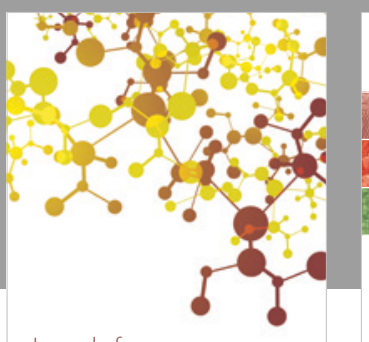

Journal of

Applied Chemistry
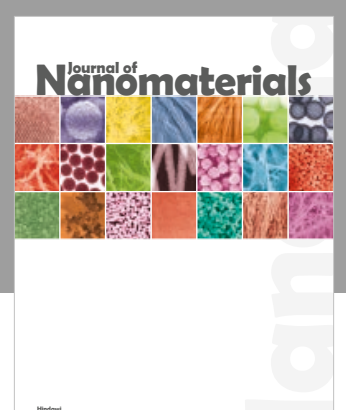

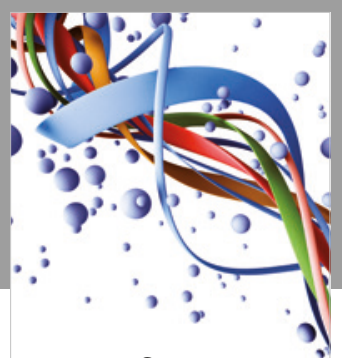

Scientifica

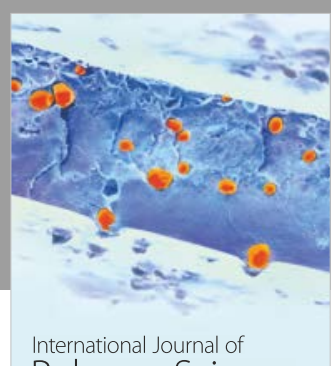

Polymer Science

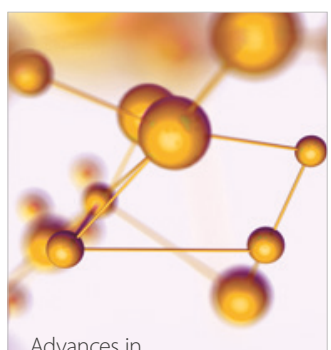

Physical Chemistry
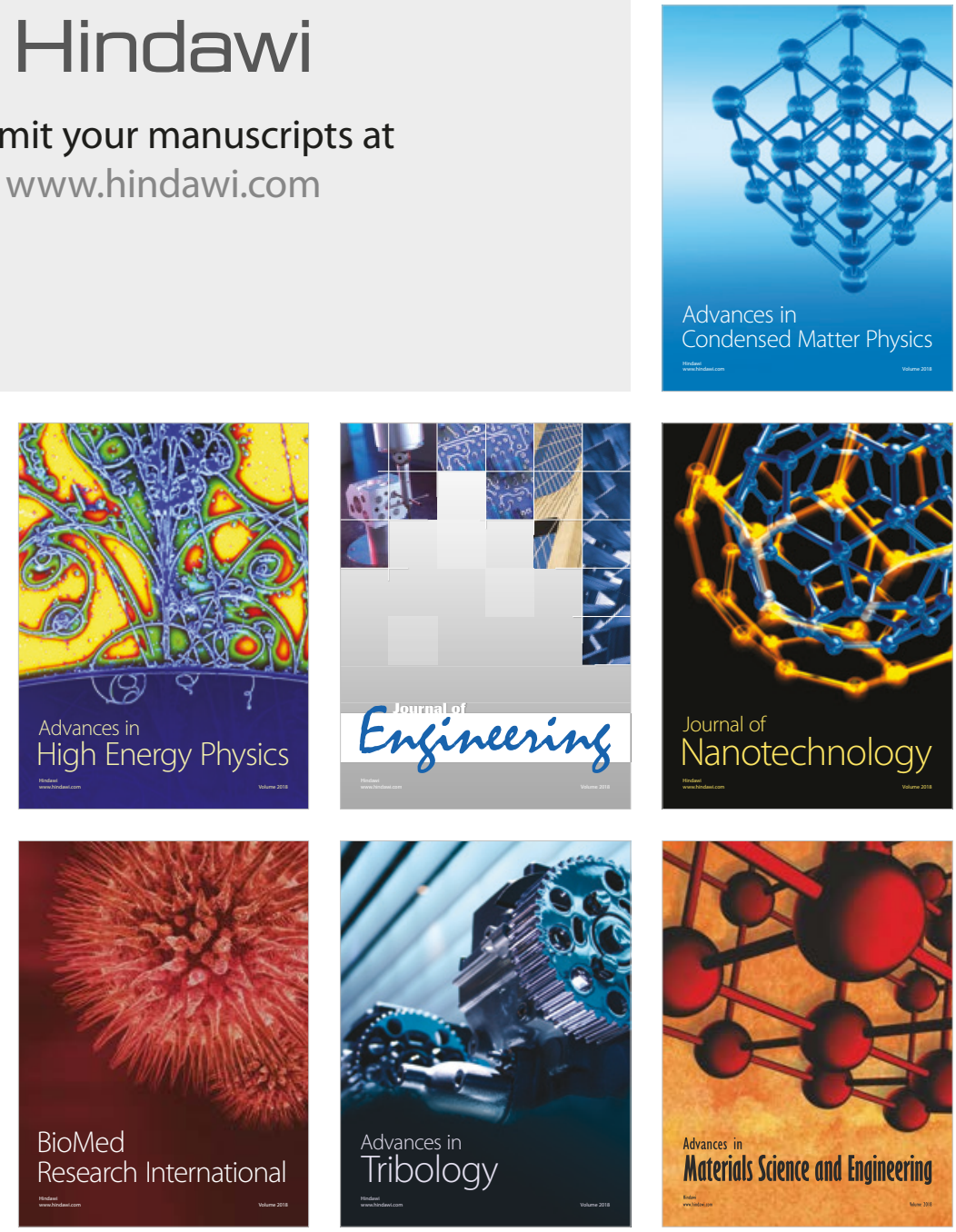